\title{
An experimental analysis of the driver's attention during train driving
}

https://doi.org/10.1515/eng-2020-0011

Received Oct 30, 2019; accepted Dec 18, 2019

\begin{abstract}
The article deals with the experimental monitoring of the driver's attention during train operation. SMI eye-tracking technology and eye-tracking glasses we used to measure the train driver's attention. This unique experiment we performed on the Slovak railway (ŽSR) line no. 120 Bratislava - Žilina, in the section Žilina - Púchov. The measurement took place in the spring of 2017, and the passenger train was operated by the ZSSK electric unit series 671. The article analyses in detail the monitoring of the driver's attention during train operation. We analysed two typical processes during train driver work: driving at the section (without stopping) and driving through the train station (with stopping). Realised analysis can lead to the identification of critical points on the line, to a better understanding of the driver's way of work and to contribute to increasing railway safety. The unique measurement procedure and the used technology did not affect the safety of the train operation.
\end{abstract}

Keywords: eye-tracking measurement, driver's attention, train operation, railway safety

\section{Introduction}

Railway transport performance in EU according to Eurostat (in 2018) was 471701.6 million passenger-kilometres and 9919851 thousand passengers. The crucial requirements for the transport system are of high quality, reasonable price, connectivity, but the most important is its safety. High level of safety in railway is based on railway signalling system. Railway signalling equipment is a set of

\footnotetext{
*Corresponding Author: Radovan Madleňák: Department of Communications, University of Žilina, 01026 Žilina, Slovakia; Email: radovan.madlenak@fpedas.uniza.sk Jaroslav Mašek: Department of Railway Transport, University of Žilina, 01026 Žilina, Slovakia

Lucia Madleňáková: Department of Communications, University of Žilina, 01026 Žilina, Slovakia
}

technical means and relations between them which contribute to the safety of railway operation. In particular, by controlling or replacing the activities of transport staff in the management of rail transport. The safety system in railway transport is modern and still upgrading. Railway transport is very safe, but like in every transport system, the human factor is still critical [1, 2].

The safety systems used in railway transport are categorised in four categories:

- Station interlocking equipment;

- Crossing interlocking device;

- Train protection system;

- Line signalling equipment.

\subsection{Train protection systems}

The train protection system is the technical equipment used on the railway tracks. It transmits signals to the traction unit to check the driver for compliance with the train's limitations (speed). In the event of a breach (over speeding or non-response to the STOP signal), the train automatically stops.

Train protection functions are:

- informing the driver of the signal to which the train is approaching;

- control driver vigilance (vigilance button, dead man's button).

The train protection system consists of trackside and mobile parts. The mobile part is placed on traction vehicles or driving cars. It can also be used to transmit and display signals to the driver's station. It includes a vigilance button.

The train protection system is a railway safety system that communicates track status and condition information to the train driver of a locomotive, railcar or multiple units [3]. The data is continually updated, giving an easy to read the display to the train driver.

The most straightforward systems display the trackside signal, while the systems that are more sophisticated also display allowable speed, location of nearby trains, and dynamic information about the track ahead. Cab sig-

OO Open Access. (C) 2020 R. Madleňák et al., published by De Gruyter. (Cc) BY 4.0 License 
nals can also be part of a more comprehensive train protection system. They can automatically apply the brakes stopping the train if the operator does not respond appropriately to a dangerous condition.

The primary purpose of a signal system is to enforce a safe separation between trains and to stop or slow trains in advance of a restrictive situation. The cab signal system is an improvement over the wayside signal system, where visual signals beside or above the right-of-way govern the movement of trains. It provides the train operator with a continuous reminder of the last wayside signal or a constant indication of the state of the track ahead.

\subsection{Train protection system types}

All train protection systems (cab signalling systems) must have a continuous in-cab indication. It informs the driver of track condition ahead; however, these fall into two main categories. Depending on the method of transmission of information from track to train, trackside train protection equipment is divided into continuous and intermittent systems.

Intermittent train protection systems at discrete points along the rail line and between these points the display will reflect information from the last update. Continuous cab signals receive a constant flow of information about the state of the track ahead and can have the cab indication change at any time to reflect any updates. The majority of cab signalling systems, including those that use coded track circuits, are continuous.

Intermittent train protection systems provide constant reminders to drivers of track conditions ahead, but they are only updated at discrete points. That can lead to situations where the information displayed to the driver has become out of date. Intermittent cab signalling systems have functional overlap with many other train protection systems such as trip stops. The difference is that a driver or automatic operating system makes continuous reference to the last received update.

Intermittent train protection systems include:

- Stopper - the forerunner of all point safeguards. It is used, for example, by the Berlin S-Bahn or the Prague metro;

- Crocodile (France, Belgium, Luxembourg);

- INDUSI and similar-PZ80, PZB90 (Germany, Austria, Romania, Canada);

- Integra-Signum (Switzerland);

- ZUB 121 (Switzerland);

- SHP (Poland);
- AWS (UK, Ireland, India);

- TPWS (UK, Northern Ireland, Australia).

Continuous train protection systems have the added benefit of failsafe behaviour in the event a train stops receiving the ongoing incident relied upon by the cab signalling system. Early systems use the rails or loop conductors laid along the track to provide continuous communication between wayside signal systems and the train. These systems provided for the transmission of more information than was possible with contemporary intermittent systems and they enabled the ability to display a miniature signal to the driver "cab signalling". Continuous systems are also more easily paired with Automatic Train Control technology, which can enforce speed restrictions based on information received through the signalling system. That is because the continuous cab signals can change at any time to be more or less restrictive, providing for more efficient operation than intermittent ATC systems. Continuous train protection systems include:

- LS (former Czechoslovakia, Czech Republic and Slovakia),

- MIREL (Slovakia and Czech Republic),

- EVM 120 (Hungary),

- RS4 Codici (Italy),

- ALSN (Russia),

- ATB (Netherlands).

\subsection{Modern train protection}

Modern train protection systems combine the advantages of both old systems - continuous information transmission (not always) along with accurate vehicle location. The most important characteristic is that the train control station receives overall information on the length and speed profile of the section ahead of the train for which the next run is permitted. If the speed limit is approaching or the end of the section is approaching, the device displays the maximum safe speed, which continuously decreases according to the brake curves. If this speed is exceeded, emergency braking is applied to prevent the train from passing beyond the leg for which it is allowed to run. These breakers eliminate the possibility of errors caused by improper operation or inattention $[4,5]$. The data transmitted to the vehicle can also be used for automatic train control.

They consist of:

- Stationary (tracked) parts (central or distributed) autonomous devices mostly dependent on the state data of SZZ, ensuring the processing of necessary information on the given route and their subsequent 
Table 1: Unauthorized driving across signalling prohibitions, including subsequent collision or derailment on national lines, regional lines and sidings (Source: Czech Rail Safety Inspection Office, 2019)

\begin{tabular}{lcccccc}
\hline & \multicolumn{3}{c}{ The year 2019 } & \multicolumn{4}{c}{ The year 2018 } \\
& No. of accidents & Train & Shunting & No. of accidents & Train & Shunting \\
\hline January & 14 & 12 & 2 & 12 & 8 & 4 \\
February & 21 & 12 & 9 & 15 & 11 & 4 \\
March & 21 & 15 & 6 & 6 & 4 & 2 \\
April & 11 & 8 & 3 & 8 & 5 & 3 \\
May & 7 & 5 & 2 & 19 & 16 & 3 \\
June & 14 & 10 & 4 & 12 & 10 & 2 \\
July & 10 & 4 & 6 & 13 & 9 & 4 \\
August & 11 & 7 & 4 & 12 & 7 & 5 \\
September & 6 & 5 & 1 & 23 & 20 & 3 \\
October & 8 & 6 & 2 & 11 & 7 & 4 \\
November & 17 & 13 & 4 & 15 & 11 & 4 \\
December & NA & NA & NA & 2 & 2 & 0 \\
No. of accidents 1.Jan. - 30.Nov. & 140 & 97 & 43 & 146 & 108 & 38 \\
No. of accidents 1.Jan. - 31.Dec. & & & & 148 & 110 & 38 \\
\hline
\end{tabular}

transfer to a moving train with a particular transfer guarantee.

- The mobile part, which is installed on individual units (or vehicles) and which receives signals or data from stationary parts, decodes them and it provides information about the next section of the train path to the driver or vehicle computer. It also calculates braking curves and exceeds the maximum safe speed (signalled or calculated according to the braking curve) triggers emergency braking.

Modern train protection systems can be well sorted by country of origin:

- SCMT (Italy);

- LZB (mainly Germany and Spain);

- ETCS (Europe);

- KLUB (Russia and former USSR countries).

The newer systems use cab signalling, where the trains regularly receive information regarding their relative positions to other trains. The computer shows the driver how fast they may drive, instead of them relying on exterior signals. These types of systems are in everyday use in France, Germany and Japan. The high speeds of these trains made it impossible for the train driver to read exterior signals, and distances between distant and home signals are too short for the train to brake.

These systems are usually far more than automatic train protection systems; not only do they prevent accidents, but also actively support the train driver [6-8].
Some of these systems being nearly able to drive the train automatically.

\subsection{Human factor as part of railway safety}

Exist many safety systems used in railway transport, but the human factor, especially in train driving is still significant. As we can see in Table 1, the numbers of safety accidents (data from Czech Rail Safety Inspection Office) are significant, and the trend is not very positive [9].

The data in Table 1 included only accidents (passing the main/shunting stop signal), not all railway accidents. $99 \%$ of this type of accident is caused by carrier train driver. It is because the driver's inadequate attention mainly causes this type of accidents during train/shunting operation. The main reason for not good driver's attention is incorrect driving skills and experiences or overworking. In railway transport, do not exist any specific safety system, which can analyse driver attention, driving skills or good/bad practise.

\section{Characteristics of the train unit and track}

In experimental measurement was used the electric double-decker multiple-unit series 671 (EPJ), which is the multiple-unit of rolling stock consisting of one electric 
traction wagon (EPV), one wagon (PVV) and one control wagon (PRV) (see Figure 1). On the upper and lower decks of the wagons, there are passenger areas with seats and the necessary equipment for travelling. The electric doubledecker car is designed to drive and control the whole set.

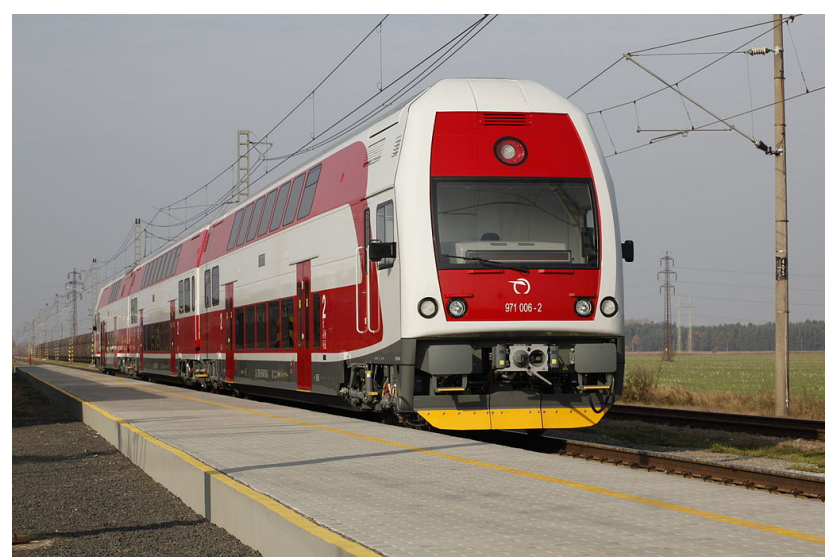

Figure 1: Electric double-decker multiple-unit series 671 (Source: Skoda Transportation)

Equipment of EPJ 671 [10]:

- number of seats: 307, of which 18 foldings (in combination electric unit $671+$ wagon $071+$ steering wagon 971);

- bicycle racks;

- low-floor access, ramp for immobile passengers;

- air condition;

- WC with a closed waste system;

- electronic information system;

- electrical outlets;

- WiFi;

- Intelligent Transport and Information System (IDIS) - selected kits;

- internal camera system;

- speed limit $160 \mathrm{~km} / \mathrm{h}$;

- AC/DC system;

- year of production: 2009-2015.

The experiment was performed on the Slovak railway (ŽSR) line no. 120 Bratislava - Žilina, in section Žilina - Púchov. The line is an electrified double-track railway line. It is part of the V Corridor, and its length is 44km [11].

The track is under significant modernisation. In 2014, began the modernisation of the line of the track section Považská Teplá - Žilina marshalling yard. After refurbishment, the maximum speed has been increased to 120-160 $\mathrm{km} / \mathrm{h}$ for conventional trains. The tilting trains can run at higher speeds thanks to the European Train Control System (ETCS). The section also installed new traction system, signalling equipment and information equipment. Total investments in this section were amount to 26.887 million $€[11]$. The construction was completed in February 2018.

In 2016 started the most demanding railway construction in the history of Slovak railways, which is the reconstruction of the last railway section between Bratislava and Žilina. By 2021, it should build a practically new line to replace the current, mostly unsatisfactory, line. In order to achieve a maximum speed of $160 \mathrm{~km} / \mathrm{h}$, the new track is intended to lead mostly on artificial structures. The new line will include two new tunnels with a length of 1081.7 $\mathrm{m}$ and $1861 \mathrm{~m}$ and six bridges, of which two bridges with a length of $379 \mathrm{~m}$ and $653 \mathrm{~m}$ over the river channel and dam [11]. Overall, the track will be shortened by $2.7 \mathrm{~km}$.

There has been selected for railway traffic control a new third category station interlocking system based on electronic interlocking with train protection (ETCS). A new line signalling device is also designed to be built with an automatic gate system with superstructure for speed control. Part of the construction is also the construction of new telecommunication technology and new data transmission systems of the mobile radio network, which allow direct radio connection of the dispatcher with moving trains. The entire track section will be controlled from the central control centre in Púchov. The reconstruction should be completed in December 2021 [11, 12]. The estimated cost is 365 million $€$, excluding VAT.

\section{Experiment - conditions and technology}

The measurement took place in the spring of 2017, and the passenger train was operated by the ZSSK electric unit series 671. The main goal of the experiment was detailed monitoring of the driver's attention during train operation. This analysis can lead to the identification of critical points on the line, to a better understanding of the driver's way of working, good, bad practice, skills and experiences to contribute to increasing railway safety. The all measurement procedure and the used measurement technology did not affect the safety of the train operation [13, 14]. Figure 2 shows the main parts (panels) of EPJ 671 working place (cabin) of the train driver, where we identified these main parts:
A. outside area;
B. rear-view mirror; 


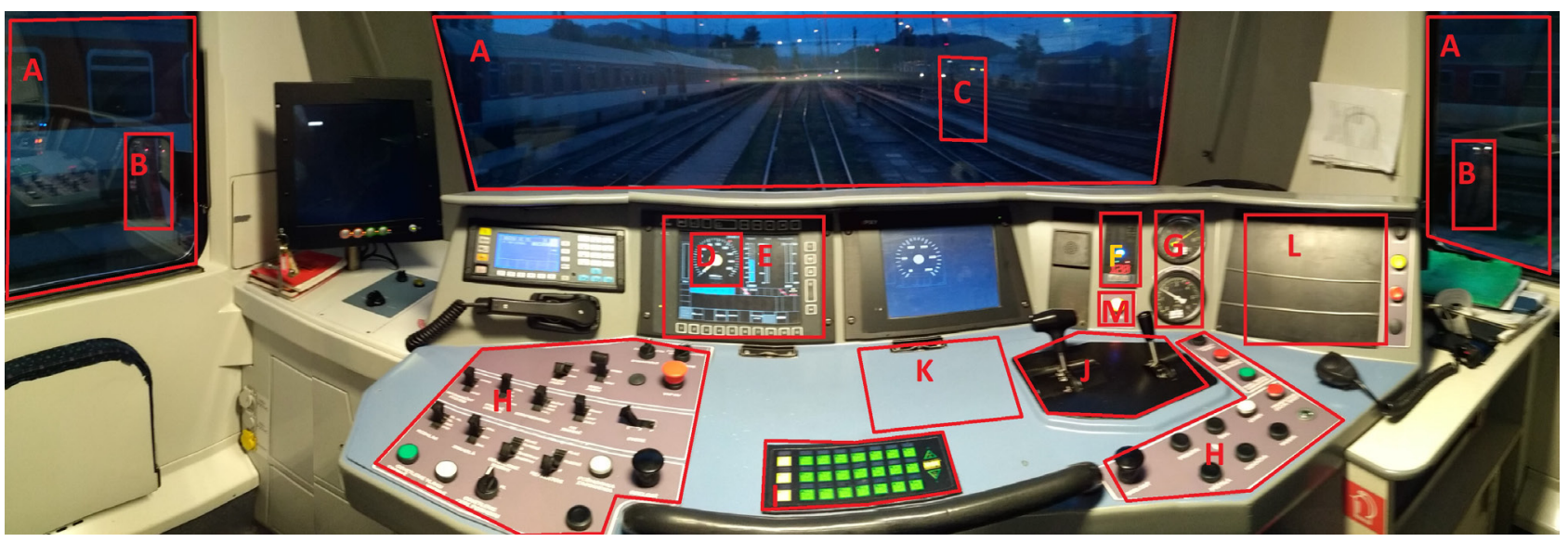

Figure 2: EPJ 671 - cabin view with monitored part/panels of the cabin

C. signals;

D. actual speed;

E. main train operating window (voltage, current, operational reports);

F. continuous cab signals train safety system Mirel;

G. pressure in the brake system;

H. train driving controllers;

I. automatic speed controller;

J. central train controller - running, braking;

K. timetable;

L. notes (for example the speed restrictions);

M. signal about train doors safety closing.

In our experiment, the train driver was 49 years old, with 28 years of praxis in international, national (longdistance) and regional railway transport. He has no accident in category A or B. A and B are the most severe and dangerous accidents, according to international railway safety rules. The average age of train driver in 2018 was in Slovak national passenger carrier 45 years and Slovak national cargo carrier 48 years. $10 \%$ of a train driver was older than 65 years, and the average age was 48,6 years and more than 300 drivers missing in the railway sector in the Czech Republic in the year 2019 [15].

We can state that the selected train driver is a typical train driver in the Slovak Republic, and he is suitable for the pilot experiment measurement.

\subsection{Aim and Methodology}

The main objective of this article is to research driver's attention during train operation on selected railway infrastructure. Based on this research, we will able to achieve the secondary objective - to understand the driver's way of work and to contribute to increasing railway safety on the selected line [16]. To be able to solve the objectives of this article, we used the following techniques and tools.

The SMI (SensoMotoric Instruments) Eye Tracking Glasses were used to collect data regarding the drivers' visual behaviour in real traffic conditions. This eye-tracking glasses with the lightweight are designed to record a person's natural gaze behaviour in real-time in a broad range of applications, see Figure 3. Glasses have on the bottom of the frame and also in the front frame placed three highspeed cameras. Two of them record the movement and position of the pupils in the eye (in the infrared spectrum), and the third camera records the surroundings (in the typical visual spectrum). The mobile phone is connected to the glasses, which visualises the surroundings on the screen and shows the point of view by the cursor. These eyetracking glasses provide native, binocular tracking at 60 $\mathrm{Hz}$ sampling rate over the whole trackable field of view. Combined with a high definition scene camera with reso-

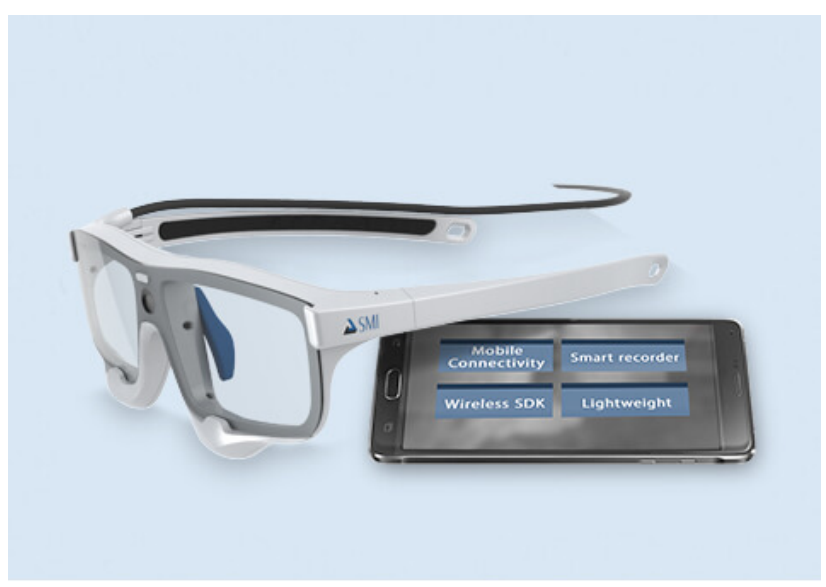

Figure 3: SMI eye-tracking glasses and mobile device (Source: hmilab.uniza.sk) 
lution 1280×960p @24 fps eventually 960×720p @30 fps and HDR (high dynamic range) mode with high sensitivity for low light and automatic parallax compensation this ensures robust and accurate data with tracking range $80^{\circ}$ horizontal, $60^{\circ}$ vertical and gaze tracking accuracy $0.5^{\circ}$ over all distances.

The SMI BeGaze software for eye-tracking provides analysing and structuring information on experiments and displaying the eye-tracking data as graphs, all in one sophisticated application. This application offers different types of analysis and results from experiments. One of the most useful for our purposes is Scan Path, or also called Gaze plot. It is a map which shows gaze fixations of the driver and in which order they occurred, based on numbered circles. The next exciting tool included in BeGaze software is AOI Editor (Areas of Interest). The AOIs can be defined for video or still images stimuli. In the function "Move\&Morph" the AOIs change their position and size during the sequence of single video frames.

All pieces of equipment (software and hardware) are parts of the Human-Machine Interaction Laboratory (HMILAB) that is located at University Science Park of University of Zilina. The HMI-LAB is oriented to provide the research and testing for the human-machine interaction in various conditions.

To fulfil the objectives mentioned above in the article, we had to set up the research procedure correctly to use the appropriate research methodology $[17,18]$. The methodology of the research is shown in the following Figure 4, and it is divided into 3 phases: preparatory, implementation and analytical phases.

In the preparatory phase of the research, we had to identify the place where the experiment will be realised the line of the railway infrastructure. We chose the railway track Žilina - Púchov. At this line, we localised two situations: drive between the two stations and drive through the station (with the stop).

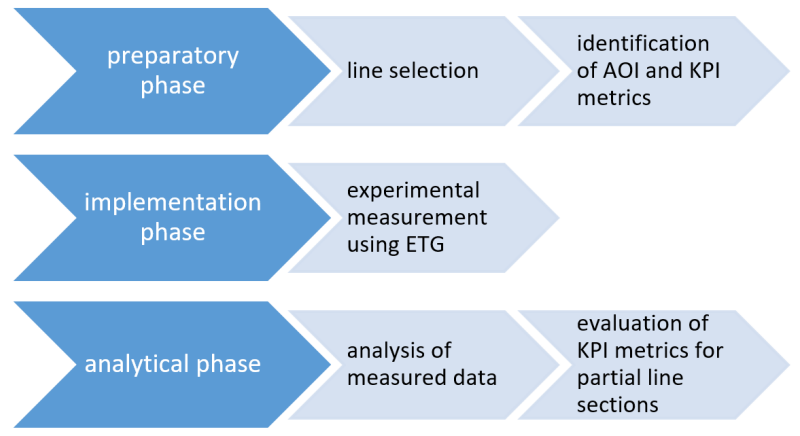

Figure 4: Methodology of research
For identification of the driver operations in the train cabin, we need to formulate the zones that are important for train control and operation. The name of these zones is the area of interests (AOI). During the experiment, we measured where (position), how long (duration), and how many times (frequency) the gaze of the driver is focused on those areas. This set of metrics we will call the key performance indicators (KPI) [19-21]. Mainly, we will detect for each AOI in the cabin these KPI (see Figure 5):

- dwell time - the total amount of time a participant fixates (fixations) or glances within an AOI (saccades). It is represented by absolute format - time in ms or relative format - $\%$ of total time,

- fixation count - the number of gaze fixation on the selected AOI,

- average fixation - the average fixation duration informs how long (in ms) the average fixation lasted for,

- revisits - the number of revisits provides information about how many times a participant returned his gaze to an AOI. The revisits allow examining which areas repeatedly attracted the participant (for better or worse), and which were seen.

These four essential KPI will play a significant role in the process of analysing train driver behaviour in real conditions.

\section{Results and discussion}

Driving behaviour, especially the train driver's gaze of eyes, was tested in light changing conditions during the daylight [22, 23]. As it is mentioned above, the gaze of the driver was captured by SMI eye-tracking glasses. Before the experiment, it was necessary to do the following steps:

- connect eye-tracking glasses to the mobile device;

- create and set up a new experiment for train driver;

- calibrate glasses and record a driver's gaze.

After successful calibration, experiment regarding of driver's gaze might begin. The total time of the experiment at the selected railroad stretch was 63 minutes and 44 seconds. As it was said in the methodology part, we focused on the two specific situations, drive between the two stations and drive through the station (with the stop). 


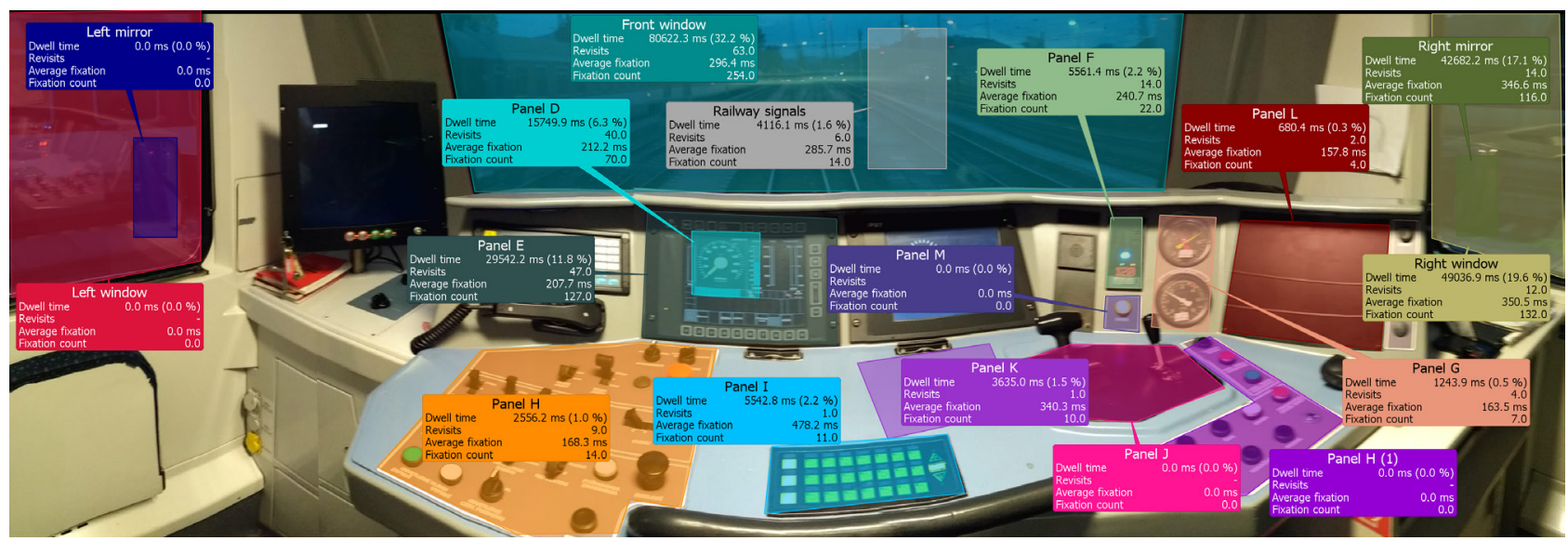

Figure 5: KPI analysis with BeGaze software

\subsection{Example 1: Drive between two stations Žilina - Horný Hričov}

The total time of drive in this section was 255 seconds. During the drive, the train driver fixated his gaze on window section $57 \%$ of the total time, on panel section $14.5 \%$ of the total time and at the railway signal section $2.9 \%$ of the total time. The number of fixations at the sections correlates with dwell time metric. More fixations on a particular AOI may indicate that the AOIs are more significant (or the AOIs are changing) and more noticeable to the driver than the others. In summary, the number of fixations on the window section was 508, on the panel section was 181 and at the railway signal section only 12 . It is logical because the scene on the frontal window is still changing.

The cognitive process of the driver is represented by the duration of average fixation at the section. We take a closer look at the particular section. The average fixation is varying from $186.5 \mathrm{~ms}$ (panel E) to $452.3 \mathrm{~ms}$ (railway signal section). It can be explained, that at the panel $\mathrm{E}$ are information that is easy to understand, and that information is displayed on the panel (bars, flashing buttons, ..). However, at the railway signal section are information that is moving in the space in front of the train and the drivers must identify the meanings of the signals.

Last KPI is the revisits. It represents how many times the gaze of train driver visited particular AOI. It shows us the real importance of the selected AOI. In this part of the train line, the most revisits have a front window part (68), and the least revisits have a panel $\mathrm{K}(0)$.

\subsection{Example 2: Drive through the station Dolný Hričov}

Another type of train driver operation is drive through the station (with stop). We analyse the drive through the station Dolný Hričov. Total time of drive in this section was 250 seconds. During the drive, the train driver concentrated his gaze on window section $71.6 \%$ of the total time, on panel section $26.7 \%$ of the total time and at the railway signal section $1.7 \%$ of the total time. These values of dwell time show that the driver was more focused on the operation as it was during the drive between the stations (security of passengers on the platform during stopping and acceleration process). When we compare the summary of fixations, on the window section was 502, on the panel section was 265 and at the railway signal section only 14 . The increased number of fixations on the panel section show needs to use, control and operate the panels during this type of operation.

When we take a look at the average fixation during this operation, we can find that the lowest average fixation is $157.8 \mathrm{~ms}$ (panel L) and the highest average fixation is at the panel I $478.2 \mathrm{~ms}$. The necessary information about the train line is located at the panel $\mathrm{L}$. The control buttons that are important for controlling the train, when it is arriving and departing the station (automatic speed control buttons) are at the panel I. Notes at the panel L have only information function, then the average fixation was very short. However, controls at the Panel I have an essential function for the train control, so the average fixations were the longest (there we can identify the cognition process of the train driver during manipulations with them).

Revisits at this particular operations show the real importance of the particular AOI. In this part of the train line, 
Table 2: KPI at the section Žilina-Horný Hričov

\begin{tabular}{lcccc}
\hline Panels & Dwell time & Fixation & Average fixation [ms] & Revisits \\
\hline Front window & $57 \%$ & 508 & 262.7 & 68 \\
Railway Signals & $2.1 \%$ & 12 & 452.3 & 9 \\
Panel D & $3.4 \%$ & 40 & 200.4 & 28 \\
Panel E & $9.6 \%$ & 112 & 186.5 & 50 \\
Panel F & $2.4 \%$ & 3 & 265.6 & 12 \\
Panel H(1) & $0.5 \%$ & 6 & 392.7 & 1 \\
Panel K & $0.7 \%$ & 276.6 & 0 \\
\hline
\end{tabular}

Table 3: KPI at the driving through Dolný Hričov station

\begin{tabular}{lcccc}
\hline Panels & Dwell time & Fixation & Average fixation [ms] & Revisits \\
\hline Front window & $32.2 \%$ & 254 & 296.4 & 63 \\
Right window & $19.6 \%$ & 132 & 350.5 & 12 \\
Right mirror & $17.1 \%$ & 116 & 346.6 & 14 \\
Railway Signals & $1.6 \%$ & 14 & 285.7 & 6 \\
Panel D & $6.3 \%$ & 70 & 212.2 & 40 \\
Panel E & $11.8 \%$ & 127 & 207.7 & 47 \\
Panel F & $2.2 \%$ & 14 & 240.7 & 14 \\
Panel H & $1.0 \%$ & 11 & 168.3 & 9 \\
Panel I & $2.2 \%$ & 10 & 478.2 & 1 \\
Panel K & $1.5 \%$ & 4 & 340.3 & 2 \\
Panel L & $0.3 \%$ & & 157.8 & 1 \\
\hline
\end{tabular}

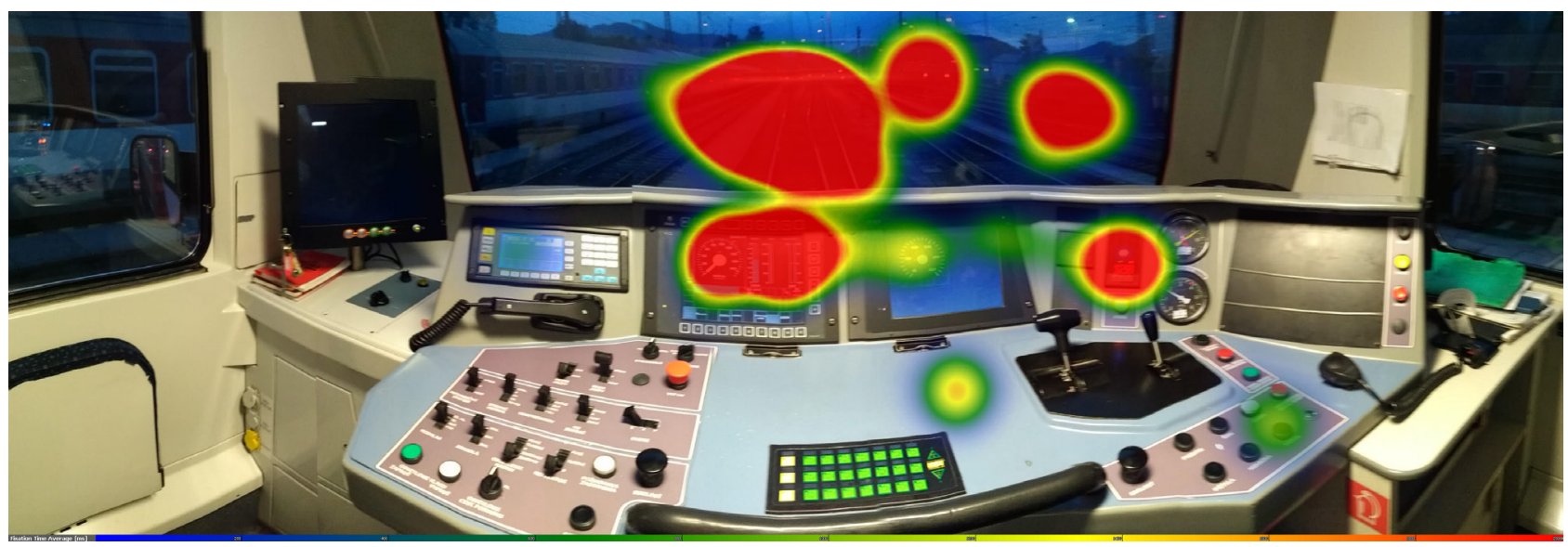

Figure 6: Heatmap of the train driver attention at the section Žilina - Horný Hričov (example 1)

the most revisits have a front window part (63), and the least revisits have a panel I (1) and $\mathrm{K}$ (1).

We analysed two different situations in real railway traffic. Now we can compare the obtained data from these two situations. Heatmaps can visualise the overall attention of the train driver. Heatmaps show the general distribution of gaze points. They are typically displayed as a colour gradient overlay on the presented image (view from the train cabin). The red, yellow, and green colours repre- sent in descending order the number of gaze points that were directed towards parts of the image.

During the driving between two stations - example 1, the train driver was mainly focused on the front window (57\% of total time and 508 fixations). Significant attention is devoted to panel $\mathrm{E}$ (9.6\% of total time and 112 fixations). It is due to the central part of the driver's work is checking the situation on the track, reading the signals, control the speed and train protection system. At Figure 6, we can 


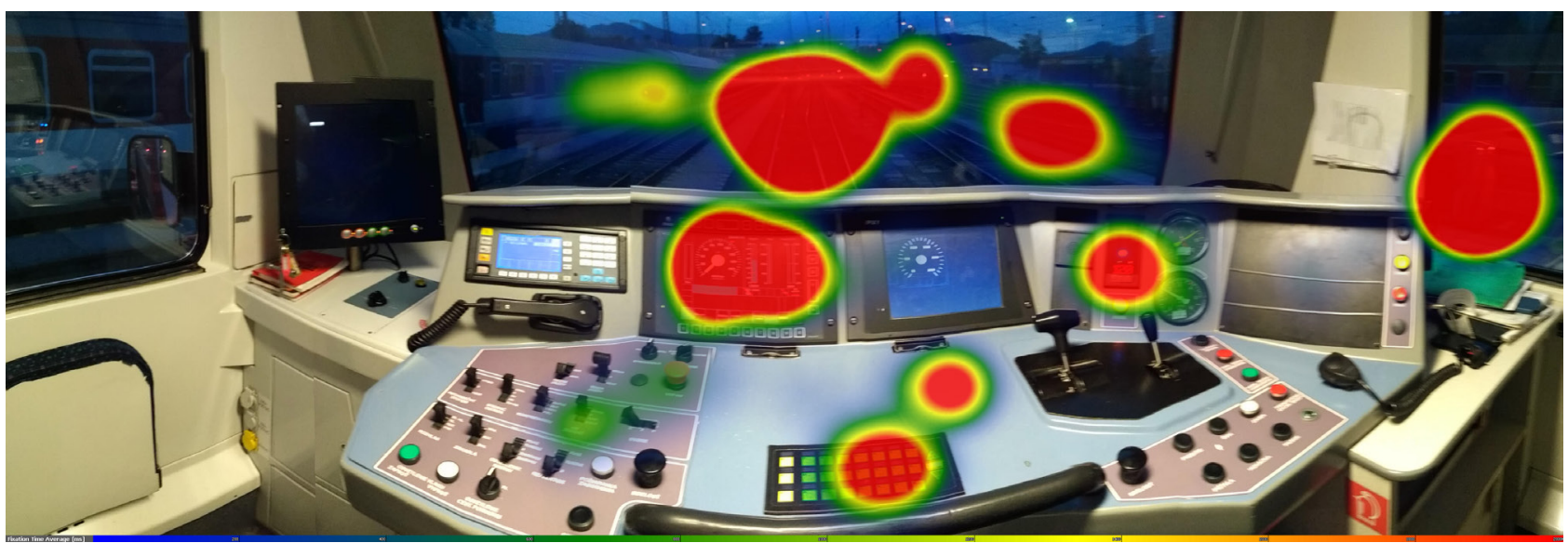

Figure 7: Heatmap of the train driver attention during driving through station Dolný Hričov

find the heatmap of this driving situation. The primary attention of the train driver is focused on the front window and the panels E, D and F. These parts of the train cabin are most important for the train operations - for the driving between the stations.

During the driving through the stations (with the stop) - example 2, the train driver was mainly focused on the front window (32.2\% of total time and 254 fixations). The attention (dwell time) and number fixations at this part of the train cabin is only half of the attention and fixations in the previous situation. Significant attention is devoted to the right window and right mirror (summary $36.7 \%$ of total time and 248 fixations). It is due to the stop at the station and visual control of passengers at the platform during stop and departing from the station. Figure 7 represents the heatmap of this driving situation. The critical attention of the train driver is focused on the front window, the right window, the right mirror and the panels $\mathrm{E}$ and $\mathrm{D}$. Identified parts of the train cabin are very important for securing the safety of arriving, stopping and departing the train from the station.

\section{Conclusions}

Safety at the railway is an actual problem. Providers of railway infrastructures and producers of trains are using many signalling and train protection systems. However, the number of accidents on the railway is increasing. The main reason for this increase is the human factor (especially train drivers behaviour). As a way how to analyse train driver behaviour in real conditions, we choose Eyetracking technology. Using experiment technics - SMI Eye Tracking Glasses and SMI BeGaze software in the field of railway transport is very innovative. Realise the experiment in real condition was the main argument for pilot testing with typical train driver in the condition of Slovak Railways. We analysed two typical processes during train driver work: driving at the section (without stopping) and driving through the train station (with stopping). The methodology of the train driver's attention analysis should be beneficial for getting detailed information about train driver work conditions, and his good/bad driving practises and experiences.

Next evolution of the experiment testing with measurements of driver attention in real conditions must be focused at:

- upgrade of the existing methodology of testing (add the additional measurement of bio signals of the train driver);

- measurements in standard work condition and extraordinary work conditions (day, night, summer and winter);

- testing driver's attention in a specific situation (collision situation);

- testing different drivers and getting information about their skills and experiences (various level of drivers experience);

- upgrading current teaching methods for train drivers (share the existing knowledge of experienced drivers to newcomers);

- preparing new testing of driver's skills (simulation of drivers behaviour in stress conditions);

- identification of the dangerous parts of railway tracks (passportisation of the railway infrastructure).

Experiment approved that these methods are usable in railway transport and have significant potential for the 
next research. All obtained information should lead to the improvement of safety in railway operation.

Acknowledgement: This contribution was undertaken as part of the research project VEGA 1/0721/18 Research on the Economic Impact of Visual Smog in Transport Using Neuroscience Methods.

\section{References}

[1] Tabai BH, Bagheri M, Sadeghi-Firoozabadi V, et al. Impact of Train Driver's Cognitive Responses on Rail Accidents. Transp Res Rec. 2018;2672(10):260-8.

[2] Hughes P, Robinson R, Figueres-Esteban M, van Gulijk C. Extracting safety information from multi-lingual accident reports using an ontology-based approach. Saf Sci. 2019;118:288-97.

[3] Hadj-Mabrouk H. Contribution of Artificial Intelligence to Risk Assessment of Railway Accidents. URBAN RAIL TRANSIT. 2019;5(2):104-22.

[4] Kendra, M., Babin, M., Barta, D., Changes of the infrastructure and operation parameters of a railway line and their impact to the track capacity and the volume of transported goods, TRANS PORT RESEARCH ARENA 2012, Book Series: Procedia Social and Behavioral Sciences, 48, 743-752

[5] Tabai BH, Bagheri M, Sadeghi-Firoozabadi V, et al. The Relationship Between Train Drivers' Attention and Accident Involvement, 4TH INTERNATIONAL CONFERENCE ON TRANSPORTATION INFORMATION AND SAFETY. ICTIS; 2017. pp. 1034-9.

[6] Kobaszynska-Twardowska A, Kadzinski A, Gill A, et al. The Risk Model for Hazards Generated at Level Crossings, INFORMATION SYSTEMS ARCHITECTURE AND TECHNOLOGY, ISAT 2018. PT III Book Series: Advances in Intelligent Systems and Computing. 2019;854:313-22.

[7] Dolinayova A, Camaj J, Kanis J. Charging Railway Infrastructure Models and their Impact to Competitiveness of Railway transport. Transp Probl. 2017;12(1):139-50.

[8] Naweed A, Young MS, Aitken J. Caught between a rail and a hard place: a two-country meta-analysis of factors that impact Track Worker safety in Lookout-related rail incidents. Theor Issues Ergon Sci. 2019;20(6):731-62.

[9] Czech The Rail Safety Inspection Office, Safety statistics 2019

[10] Slovak Railways (ŽSR), Track no. 120, technical information

[11] Skoda Transportation, Technical characteristics of EPJ series 671

[12] Fabus J, Nemcek B, Kremenova I. Usability of eyetrack technology for educational institutions. 7th International Technology, Education and Development Conference (INTED), 2013, Mar 04-06, Valencia, SPAIN.
[13] Hudak M, Madlenak R. The research of driver's gaze at the traffic signs. In CBU International Conference Proceedings 2016: Innovations in Science and Education, 2016, Prague, 896-899 https://doi.org/10.12955/cbup.v4.870.

[14] Luptak V, Drozdziel P, Stopka O, Stopkova M, Rybicka I. Approach methodology for comprehensive assessing the public passenger transport timetable performances at a regional scale. Sustainability. 2019;11(13):3532.

[15] Stopka O, Chovancova M, Kampf R. Proposal for streamlining the railway infrastructure capacity on the specific track section in the context of establishing an integrated transport system. In: MATEC Web of Conferences, Vol. 134, Article number 00055, 18th International Scientific Conference, LOGI 2017; Ceske Budejovice; Czech Republic; 19 October 2017; Code 131750. https: //doi.org/10.1051/matecconf/201713400055.

[16] Lizbetin J, Ponicky J, Zitricky V. The throughput capacity of rail freight corridors on the particular railways network. Nase More (Dubr). 2016;63(3):161-9.

[17] Nedeliakova E, Sekulova J, Nedeliak I, Majercak P. Safety of Level Crossings from Society-Wide Perspective. In: Transport Means 2014 - Proceedings of the 18th International Conference, OCT 23-24, 2014, Kaunas Univ Technol, Kaunas, LITHUANIA, 326-328

[18] Novak, A., Havel, K., Adamko, P. Number of conflicts at the route intersection - minimum distance model. AVIATION 23(1), 1-6, DOI: https://doi.org/10.3846/aviation.2019.9746.

[19] Jarasuniene A, Yatskiv I. Analysis of improvement of road safety using intelligent transport systems (ITS). In: Transport Means 2007, Proceedings, Kaunas: Kaunas Univ Technology Press, 82185.

[20] Madlenak R, Hudak M. The Research of Visual Pollution of Road Infrastructure in Slovakia. In: Challenge of Transport Telematics, TST 2016, vol. 640. Cham: Springer Int Publishing Ag. 415-425

[21] Blaho P, Šulko P, Černá L, Dolinayová A. Draft proposal of determining charges for stabling of rolling stock within the ŽSR railway network. 18th International scientific conference LOGI 2017, no. 134. London: Édition Diffusion Presse Sciences, 2017. 1-8

[22] Madlenak R, Hudak M. Analysis of Roadside Advertisements on Selected Road Stretch in Zilina. In Proceedings of the 20th International Scientific Conference Transport Means 2016, Kaunas: Kaunas Univ Technology Press, 618-621.

[23] Sun CZ, Zhang GL, Zhai XJ. Research on Specific Eye Movement Mode of Qualified Railway Driver. In: International Symposium on Power Electronics and Control Engineering (ISPECE), 2018, Dec 28-30, Xian Univ Technol, Xian, Peoples R China https://doi. org $/ 10.1088 / 1742-6596 / 1187 / 5 / 052083$ 